\title{
I nstituições Eletrônicas no Desenvolvimento de Jogos de Empresas Para o Treinamento de Coordenadores de Cursos de Graduação
}

\author{
Giliane Bernardi \\ Orientador: Antônio Carlos da Rocha Costa \\ Data da defesa: 08 de janeiro de 2009
}

A gestão de cursos de graduação, no âmbito da coordenação de curso, está relacionada à execução de práticas que visam à melhoria da qualidade de ensino, pesquisa e extensão. No entanto, o que se observa, na maioria dos casos, é que os gestores não apresentam conhecimento aprofundado sobre os processos que estão sob sua responsabilidade, no que se refere ao fluxo de atividades e informações, devido, usualmente, a pouca qualificação ao assumirem cargos administrativos, ocorrendo uma necessidade de profissionalização da gestão. Esta tese propõe o treinamento de coordenadores de cursos de graduação, no que concerne aos seus processos de negócio, através da utilização de Jogos de Empresa. A mesma apresenta o jogo Simulador de Processos Organizacionais baseado em Instituições Eletrônicas (SPOIE), que pretende auxiliar o coordenador de curso a conhecer melhor o fluxo dos processos, os participantes envolvidos em cada processo, bem como as interações que devem ocorrer durante sua realização. A abordagem de Instituições Eletrônicas e Agentes de Software é utilizada de forma a prover mecanismos de representação das diversas interações existentes nos processos institucionais. Por fim, é apresentada uma análise da aplicação do SPOIE à coordenadores de cursos de graduação de diferentes Instituições de Educação Superior. Com a implementação da ferramenta e a aplicação realizada, percebe-se que é possível desenvolver um treinamento autônomo dos coordenadores de curso de graduação, no que concerne aos seus processos administrativos, com a abordagem supracitada.

Palavras-chave: Gestão universitária. Aprendizagem organizacional. Jogos de empresa. Agentes de Software. Instituições Eletrônicas.

Referência: BERNARDI, Giliane. Instituições Eletrônicas no Desenvolvimento de Jogos de Empresas Para o Treinamento de Coordenadores de Cursos de Graduação. Orientador: Antônio Carlos da Rocha Costa. 2008. Tese (doutorado) - Programa de Pós-Graduação em Informática na Educação, Centro de Estudos Interdisciplinares em Novas Tecnologias da Educação, Universidade Federal do Rio Grande do Sul, 2008, Porto Alegre. 